\title{
Liquid phase adsorptions of Rhodamine B dye onto raw and chitosan supported mesoporous adsorbents: isotherms and kinetics studies
}

\author{
A. A. Inyinbor ${ }^{1,2}$ F. A. Adekola ${ }^{2}$ G. A. Olatunji ${ }^{2}$
}

Received: 21 November 2015/Accepted: 17 March 2016/Published online: 4 April 2016

(C) The Author(s) 2016. This article is published with open access at Springerlink.com

\begin{abstract}
Irvingia gabonensis endocarp waste was charred (DNc) and subsequently coated with chitosan $(\mathrm{CCDNc})$. Physicochemical characteristics of the two adsorbents were established, while Fourier transform infrared (FTIR), Scanning electron microscopy (SEM) and Brunauer-Emmett-Teller (BET) surface area methods were further employed for characterization. Efficiencies of the prepared adsorbents in the uptake of Rhodamine B $(\mathrm{RhB})$ from aqueous effluent were investigated and adsorption data were tested using four isotherms and four kinetics models. The BET surface areas of the prepared adsorbent were 0.0092 and $4.99 \mathrm{~m}^{2} / \mathrm{g}$ for $\mathrm{DNc}$ and CCDNc, respectively, and maximum adsorption was recorded at $\mathrm{pH}$ between 3 and 4 , respectively. While monolayer adsorption dominates the uptake of $\mathrm{RhB}$ onto $\mathrm{DNc}$, uptake of RhB onto CCDNc was onto heterogeneous surface. The maximum monolayer adsorption capacities $\left(q_{\max }\right)$ obtained from the Langmuir equation are 52.90 and $217.39 \mathrm{mg} / \mathrm{g}$ for DNc and CCDNc, respectively. Pseudo second order and Elovich kinetic models well described the kinetics of the two adsorption processes. The mean sorption energy $(E)$ calculated from the D-R model and desorption efficiencies suggests that while the uptake of $\mathrm{RhB}$ onto DNc was physical in nature, for RhB-CCDNc system chemisorption dominates.
\end{abstract}

A. A. Inyinbor

inyinbor.adejumoke@landmarkuniversity.edu.ng

$\triangle$ F. A. Adekola

fadekola@unilorin.edu.ng

1 Department of Physical Sciences, Landmark University, P.M.B 1001, Omu Aran, Nigeria

2 Department of Industrial Chemistry, University of Ilorin, P.M.B 1515, Ilorin, Nigeria
Keywords Irvingia gabonensis · Biomass · Rhodamine B · Adsorption · Isotherms · Kinetics

\section{Introduction}

Adsorption of pollutants using commercial activated carbon has gotten wide acceptance due to its simplicity of operation viz-a-viz ability to remove very low concentration of pollutants (El Haddad et al. 2013; Huang et al. 2015). Precursors employed in the preparation of commercial activated carbon renders it very expensive. Quest for cheap and effective adsorbents as alternative to commercial activated carbon is a major concern to environmentalists.

Agricultural waste consists of cellulose, hemicellulose and other functional groups which makes them a suitable alternative to commercial activated carbon. Agricultural wastes are highly abundant, cheap and sometimes a nuisance to the environment, therefore their applications in environmental remediation will lead to environmental protections and waste management. Agricultural wastes are efficient in the uptake of heavy metals, dyes and other complex organic compounds (Salleh et al. 2011; El Haddad et al. 2014b).

Thermal treatment, chemical activation and surface modification among others can effectively enhance the adsorption potential of raw agricultural wastes. The release of water from the matrix of agro waste as well as elimination of volatile organic compounds during thermal treatment may result in pore creation in agro waste (Mohan et al. 2011; Deveci and Kar 2013). Such pores are good medium of transporting pollutants into the adsorbents. Surface modification provides active sites on biomass for enhanced pollutant adsorption.

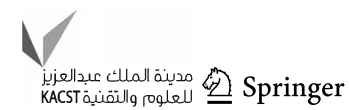


Chitosan is a readily available sea material low cost adsorbent; it is the $N$-deacetylated derivative of chitin and exists naturally in fungal cell walls (Meng Qin and Lu Dewei 2000; Zhao et al. 2012). Chitosan is an effective adsorbent for the uptake of dyes and heavy metals due to the free, highly reactive amino groups exposed during deacetylation. The presence of both amino and hydroxyl groups in chitosan qualifies it for the adsorption of cationic and anionic dyes. Chitosan currently stands as one of the potent adsorbents for the treatment of dye wastewater (Sheshmani et al. 2014).

Various adsorbents have been utilized in dye removal from aqueous solutions viz; animal bone meal (El Haddad et al. 2012), sugar beet pulp (Akar et al. 2013), calcined eggshell (Slimani et al. 2014), modified durian seed (Ahmad et al. 2015), and oat hull (Banerjee et al. 2016). The present study, however, presents a novel adsorbent that combines the reactive site of chitosan with the mesopores generated via thermal treatment on the endocarp of Irvingia gabonensis. The idea of the present study is to provide possible dual effective sorption sites (reactive surface and pores for entrapment) for the sorption of Rhodamine B dye. The prepared bioadsorbents were characterized in order to understand the porosity, morphology, and surface chemistry of the adsorbents. Their adsorption potential in the uptake of $\mathrm{RhB}$ was investigated; various adsorption operational parameters such as effect of $\mathrm{pH}$, initial adsorbate concentration/contact time and temperature were fully reported. Kinetics, isotherm and thermodynamics studies were employed to test the mechanism and process of RhB adsorption. Studies of regeneration of the spent adsorbent were also carried out and reported.

\section{Materials and methods}

\section{Materials}

Analytical grade chemicals were used in this work. Chitosan flakes were supplied by Sigma Aldrich while Rhodamine B (RhB) was supplied by BDH. The endocarp of $I$. gabonensis (dika nut-DN) was collected from local farmers in Omu Aran, Kwara State, Nigeria.

\section{Adsorbent preparation}

\section{Thermal treatment of Irvingia gabonensis}

The endocarp of I. gabonensis (dika nut-DN) was thermally treated in a muffle furnace operated at $500{ }^{\circ} \mathrm{C}$ for about $3 \mathrm{~h}$; the carbon obtained was ground and screened into a particle size of $150-250 \mu \mathrm{m}$. It was stored in an air tight container and labeled DNc.
Preparation of chitosan coated DNc $(C C D N c)$

Chitosan gel was prepared via addition of $2 \mathrm{~g}$ of chitosan flakes to $100 \mathrm{~mL}$ of $2 \%$ acetic acid and stirring the mixture for $4 \mathrm{~h}$. A $10 \mathrm{~g}$ of DNc was subsequently washed with $2 \%$ acetic acid solution and was added to $100 \mathrm{~mL}$ of $2 \%$ chitosan gel, it was then stirred with a magnetic stirrer for $4 \mathrm{~h}$. Excess acid was neutralized using $0.1 \mathrm{M}$ $\mathrm{NaOH}$ and subsequent washing to neutrality carried out with deionised water. The residue was dried in an oven operated at $40{ }^{\circ} \mathrm{C}$ and the dried samples stored in an air tight container.

\section{Adsorbents characterization}

BET surface area and average pore diameter were determined using a Micrometrics Tristar II surface area and porosity analyzer. Samples were degassed under vacuum at $90{ }^{\circ} \mathrm{C}$ for $1 \mathrm{~h}$ and the temperature was further increased to $200{ }^{\circ} \mathrm{C}$ overnight. FEIESEM Quanta 200 for SEM was employed to establish the surface morphology of the adsorbents. Bruker Alpha FTIR spectrometer was used for functional group determination while pHpzc was done following a method described in our previous study (Inyinbor et al. 2015).

\section{Adsorbate used and adsorbate preparations}

The properties of Rhodamine B are presented in Table 1, A stock solution of $\mathrm{RhB}(1000 \mathrm{mg} / \mathrm{L})$ was prepared and serial dilution was made to obtain other lower concentrations required.

\section{Batch adsorption studies}

Batch adsorption studies with focus on various adsorption parameters such as initial solution $\mathrm{pH}$ ( $\mathrm{pH}$ 2-9), adsorbent dosage (1-5 g/L), initial $\mathrm{RhB}$ concentration, contact time (50-400 $\mathrm{mg} / \mathrm{L})$ and temperature $(303-333 \mathrm{~K})$ on the removal of $\mathrm{RhB}$ were carried out. The $\mathrm{pH}$ of the $\mathrm{RhB}$ solution was adjusted by adding $0.1 \mathrm{M} \mathrm{HCl}$ or $0.1 \mathrm{M}$ $\mathrm{NaOH}$. In each adsorption experiment, $0.1 \mathrm{~g}$ of the adsorbent was added to $100 \mathrm{~cm}^{3}$ samples of $\mathrm{RhB}$ solution of a specific concentration in a $250 \mathrm{~cm}^{3}$ glass conical flask. The flask was agitated for predetermined time in a thermostated water bath shaker operated at fixed temperature and $130 \mathrm{rpm}$ to reach equilibrium. Then the adsorbent was separated from solution by centrifugation. The concentration of unadsorbed dye was determined using a Beckman Coulter Du 730 UV-Vis spectrophotometer set at $554 \mathrm{~nm}$. Quantity adsorbed at a given time $\mathrm{t}$ was calculated using Eq. 1 and percentage removal was obtained using Eq. 2: 
Table 1 Properties of Rhodamine B

\begin{tabular}{ll}
\hline Parameters & Values \\
\hline Suggested name & Rhodamine B \\
C.I number & 45,170 \\
C.I name & Basic violet 10 \\
Class & Rhodamine \\
$\lambda_{\text {max }}$ & $554 \mathrm{~nm}$ \\
Molecular formular & $\mathrm{C}_{28} \mathrm{H}_{31} \mathrm{~N}_{2} \mathrm{O}_{3} \mathrm{Cl}$ \\
Molecular weight & 479.02 \\
Chemical structure &
\end{tabular}

$q_{t}=\frac{\left(C_{i}-C_{t}\right) \times V}{M}$

$\%$ Removal $=\frac{\left(C_{i}-C_{f}\right)}{C_{i}} \times 100$

where $C_{i}, C_{t}$ and $C_{f}$ are the initial concentration, the concentration of RhB at time $t$ and final concentration of RhB, respectively. $V$ is the volume of $\mathrm{RhB}$ solution used for the adsorption studies in liter and $M$ is the weight of the adsorbent in grams.

\section{Mathematical modeling}

Isothermal studies Isothermal studies gives insight into the equilibrium relationship of the amount of adsorbate uptake onto the adsorbent (Ahmad et al. 2015). Equilibrium adsorption data were analyzed using the Langmuir, Freundlich, Temkin and Dubinin-Radushkevich (D-R) adsorption models.

Langmuir isotherm The Langmuir isotherm (Langmuir 1916) which assumes a surface with homogeneous binding sites that suggests that adsorption is onto a uniform site. Linear form of Langmuir equation is expressed by Eq. 3 while the dimensionless factor $R_{L}$ that suggests favorability of adsorption process is given by Eq. $3 \mathrm{a}$;

$\frac{C_{e}}{q_{e}}=\frac{C_{e}}{q_{\max }}+\frac{1}{q_{\max } K_{L}}$

$R_{L}=\frac{1}{\left(1+K_{L} C_{o}\right)}$ where $C_{e}$ is the equilibrium concentration of $\mathrm{RhB}$ dye $(\mathrm{mg} /$ $\mathrm{L}), q_{e}$ is the quantity of $\mathrm{RhB}$ dye adsorbed onto the adsorbent at equilibrium $(\mathrm{mg} / \mathrm{g}), q_{\max }$ is the maximum monolayer adsorption capacity of adsorbent $(\mathrm{mg} / \mathrm{g})$ and $K_{\mathrm{L}}$ is the Langmuir adsorption constant $(\mathrm{L} / \mathrm{mg})$.

Freundlich isotherm The Freundlich isotherm (Freundlich 1906) describe multilayer adsorption in which adsorption is onto heterogeneous or non uniform surface. The linear form of Freundlich equation is expressed as Eq. 4;

$\log q_{e}=\frac{1}{n} \log C_{e}+\log K_{f}$

$K_{f}$ and $n$ are Freundlich constants incorporating the factors affecting the adsorption capacity and adsorption intensity, respectively. $C_{e}$ is the equilibrium concentration of $\mathrm{RhB}$ dye $(\mathrm{mg} / \mathrm{L}), q_{e}$ is the quantity of $\mathrm{RhB}$ dye adsorbed onto the adsorbent at equilibrium (mg/g).

Temkin isotherm The Temkin isotherm (Temkin and Pyzhev 1940) assumes linear rather than logarithmic decrease of heat of adsorption while ignoring extremely low and very high concentrations. The linear form of Temkin adsorption isotherm equation is expressed by Eq. 5;

$q_{e}=\mathrm{B} \ln A+\mathrm{B} \ln C_{e}$.

$A$ is the Temkin isotherm constant $(\mathrm{L} / \mathrm{g})$, from the value of Temkin constant $B, b(\mathrm{~J} / \mathrm{mol})$ which is a constant related to the heat of absorption can be obtained from the expression $B=R T / b, T$ is the temperature $(\mathrm{K}), R$ is the gas constant $(8.314 \mathrm{~J} / \mathrm{mol} \mathrm{K}) . C_{e}$ is the equilibrium concentration of $\mathrm{RhB}$ dye $(\mathrm{mg} / \mathrm{L}), q_{e}$ is the quantity of $\mathrm{RhB}$ dye adsorbed onto the adsorbent at equilibrium $(\mathrm{mg} / \mathrm{g})$.

Dubinin Radushkevich (D-R) isotherm Dubinin Radushkevich (D-R) model (Dubinin and Radushkevich 1947) gives insight into the adsorbent porosity as well as the adsorption energy $(E)$. The value $E$ further provides information as to whether adsorption process is physical or chemical in nature. The linear equation for the D-R isotherm model is expressed by Eq. 6, Polanyi potential ( $(\varepsilon)$ and the mean energy of adsorption $(E)$ can be obtained by Eqs. 6a and 6b, respectively;

$\ln q_{e}=\ln q_{o}-\beta \varepsilon$

$\varepsilon=R T \ln \left(1+\frac{1}{C_{e}}\right)$

$E=\sqrt{1} / 2 \beta$

$\beta$ which is the activity coefficient, $T$ is the temperature $(\mathrm{K})$, $R$ is the gas constant $(8.314 \mathrm{~J} / \mathrm{mol} / \mathrm{K}) . C_{e}$ is the equilibrium 
concentration of $\mathrm{RhB}$ dye $(\mathrm{mg} / \mathrm{L}), q_{e}$ is the quantity of $\mathrm{RhB}$ dye adsorbed onto the adsorbent at equilibrium $(\mathrm{mg} / \mathrm{g})$.

\section{Kinetics model}

Kinetic studies that depend on the effects of contact time on $\mathrm{RhB}$ uptake onto the prepared adsorbents were well investigated. The kinetic of the adsorption systems were studied using the pseudo first order, pseudo second order, Elovich and Avrami kinetic models. Intraparticle diffusion model was employed in the investigation of the mechanism of adsorption.

Pseudo first order kinetic model Pseudo first-order kinetic model of Lagergren (Lagergren and Svenska 1898) is expressed by Eq. 7;

$\ln \left(q_{e}-q_{t}\right)=\ln q_{e}-K_{1} t$

where $q_{e}$ is the quantity adsorbed at equilibrium $(\mathrm{mg} / \mathrm{g})$ and $q_{t}$ is the quantity absorbed at time $t(\mathrm{mg} / \mathrm{g})$ and $k_{1}$ is the rate constant for the pseudo first order sorption in $\mathrm{min}^{-1}$.

Pseudo second order kinetic model Pseudo second order kinetic model (Ho and McKay 1999) is expressed by Eq. 8;

$\frac{t}{q_{t}}=\frac{1}{k_{2} q_{e}^{2}}+\frac{t}{q_{e}}$

where $q_{e}$ is the quantity adsorbed at equilibrium $(\mathrm{mg} / \mathrm{g})$ and $q_{t}$ is the quantity absorbed at time $t(\mathrm{mg} / \mathrm{g})$ and $K_{2}$ is the rate constant of the pseudo second order kinetic model in $\mathrm{g} / \mathrm{mg} \mathrm{min}^{-1}$.

Elovich kinetic model The linear form of Elovich kinetic model (Aharoni and Ungarish 1976) is expressed by the Eq. 9;

$q_{t}=\frac{1}{\beta} \ln (\alpha \beta)+\frac{1}{\beta} \ln t$

where $q_{t}$ is the quantity of adsorbate adsorbed at time $t(\mathrm{mg} / \mathrm{g}), \alpha$ is a constant related to chemisorption rate and $\beta$ is a constant which depicts the extent of surface coverage. The two constants $(\alpha$ and $\beta$ ) can be calculated from the intercept and slope of the plot of $q_{t}$ versus lnt, respectively.

Avrami kinetic model The linearized Avrami kinetic model equation (Avrami 1940) is expressed by Eqs. 10;

$\ln [-\ln (1-\alpha)]=n_{\mathrm{AV}} K_{\mathrm{AV}}+n_{\mathrm{AV}} \ln t$

$K_{\mathrm{Av}}$ is the Avrami constant and $n_{\mathrm{Av}}$ is the Avrami model exponent of time related to the change in mechanism of adsorption. $K_{\mathrm{Av}}$ and $n_{\mathrm{Av}}$ can be obtained from the intercept and slope of the plot of $\ln [-\ln (1-\alpha)]$ against $\operatorname{lnt}$.
Intraparticle diffusion model Intraparticle diffusion model by Weber and Morris (Weber and Morris 1963) is expressed by Eq. 11;

$q_{t}=K_{\mathrm{diff}} t^{1 / 2}+C$

where $q_{t}$ is the quantity absorbed at time $t(\mathrm{mg} / \mathrm{g})$ and $K_{\text {diff }}$ is the rate constant for intraparticle diffusion $\left(\mathrm{mg} \mathrm{g}^{-1}\right.$ $\min ^{-1 / 2}$ ). Insight into the thickness of the boundary layer can be obtained from the value of $C$; a large intercept suggests great boundary layer effect.

\section{Validation of adsorption kinetics}

Chi square, which is given by Eqs. 12, was used to validate the kinetics model.

$\chi^{2}=\sum_{i=1}^{n} \frac{\left(q_{\mathrm{exp}}-q_{\mathrm{cal}}\right)^{2}}{q_{\mathrm{cal}}}$

\section{Thermodynamic studies}

Effect of temperature on the uptake of $\mathrm{RhB}$ onto the adsorbents was studied; thermodynamic parameters that explain feasibility, spontaneity and the nature of adsorbateadsorbent interactions $\left(\Delta G^{\mathrm{o}}, \Delta H^{\mathrm{o}}\right.$ and $\left.\Delta S^{\mathrm{o}}\right)$ were calculated using the mathematical relations 13 and 14;

$\ln K_{o}=\frac{\Delta S^{\circ}}{R}-\frac{\Delta H^{\circ}}{\mathrm{RT}}$

$\Delta G^{\mathrm{O}}=-\mathrm{RT} \ln K_{\mathrm{O}}$

where $T$ is the temperature in Kelvin, $R$ is the gas constant and $K_{o}$ can be obtained from $q_{e} / C_{e} . \Delta H^{\mathrm{o}}$ and $\Delta S^{\mathrm{o}}$ can be obtained from the plot of $\ln \mathrm{K}_{\mathrm{o}}$ versus $1 / T$.

\section{Spent adsorbent regeneration studies}

In order to further ascertain the mode of $\mathrm{RhB}$ uptake onto the adsorbent used, leaching/desorption of RhB from DNC and $\mathrm{CCDNc}$ was investigated using deionized water, $0.1 \mathrm{M}$ $\mathrm{HCl}$ and $0.1 \mathrm{M} \mathrm{CH}_{3} \mathrm{COOH}$. $0.1 \mathrm{~g}$ of each fresh adsorbent was loaded with $\mathrm{RhB}$ by agitating mixture of $0.1 \mathrm{~g}$ and $100 \mathrm{~cm}^{3}$ of $100 \mathrm{mg} / \mathrm{L} \mathrm{RhB}$ solution at optimum $\mathrm{pH}$ of each adsorbent for $1 \mathrm{~h}$. The RhB $\backslash$ loaded-adsorbent was separated by centrifugation and the residual $\mathrm{RhB}$ concentration determined spectrophotometrically. The RhB loaded-adsorbent was washed gently with water to remove any unadsorbed dye and dried. The desorption process was carried out by mixing $100 \mathrm{~cm}^{3}$ of each desorbing eluent with the dried loaded-adsorbent and shaking the mixture for a predetermined time, and the desorbed $\mathrm{RhB}$ was determined spectrophotometrically. Desorption efficiency was calculated using the mathematical relation below; 
Table 2 Characteristics of DNc and CCDNc

\begin{tabular}{llc}
\hline Parameters & \multicolumn{2}{l}{ Values } \\
\cline { 2 - 3 } & DNc & CCDNc \\
\hline $\mathrm{pH}$ & 6.07 & 5.71 \\
$\mathrm{pH}_{\mathrm{pzc}}$ & 6.60 & 6.00 \\
Bulk density $\left(\mathrm{g} \mathrm{cm}^{-3}\right)$ & 1.25 & 0.50 \\
Moisture content $(\%)$ & 1.57 & 1.03 \\
Ash content $(\%)$ & 1.77 & 0.79 \\
BET surface area $\left(\mathrm{m}^{2} \mathrm{~g}^{-1}\right)$ & 0.0092 & 4.9883 \\
Average pore diameter $(\mathrm{nm})$ & $\mathrm{nd}$ & 43.93 \\
\hline
\end{tabular}

$n d$ not detectable

Desorption efficiency $(\%)=\frac{q_{\mathrm{de}}}{q_{\mathrm{ad}}} \times 100$

where $q_{\text {de }}$ is the quantity desorbed by each of the eluent and $q_{\text {ad }}$ is the adsorbed quantity during loading.

\section{Results and discussion}

\section{Characterization of DNc and CCDNc}

\section{Physicochemical characterization}

Characteristics of DNc and CCDNc are listed in Table 2. Very low ash content characterizes DNc and CCDNc, this suggest that they are easily degradable. BET surface area was found to be low for both adsorbents (Table 2). Surface modification, however, slightly increased the surface area. Low surface areas have been previous reported as characteristics of agro waste (Zhang et al. 2013). Average pore diameter of CCDNc was found to be within the mesopore region, mesopores are large enough to trap large molecules such as RhB into the adsorbents (Sayğılı and Güzel 2016).

\section{Functional group analysis}

Strong absorption bands observed in DN at 1062, 2950 and $3382 \mathrm{~cm}^{-1}$ can be attributed to $\mathrm{C}-\mathrm{OH}, \mathrm{CH}_{2}$, and $-\mathrm{OH}$ vibrations, respectively. After thermal treatment, dehydration, break down of hemicellulose coupled with elimination of volatile organic compounds results in the disappearance of these absorption bands (Fig. 1a). The FTIR spectrum of CCDNc revealed vivid peaks at 1221 and $1594 \mathrm{~cm}^{-1}$; these are characteristic bands for $\mathrm{C}-\mathrm{N}$ stretching vibrations and $\mathrm{NH}_{2}$ scissoring vibrations, respectively.

\section{Surface morphology}

The surface morphology of DNc and CCDNc before and after $\mathrm{RhB}$ uptake is shown in Fig. 2. Comparing the
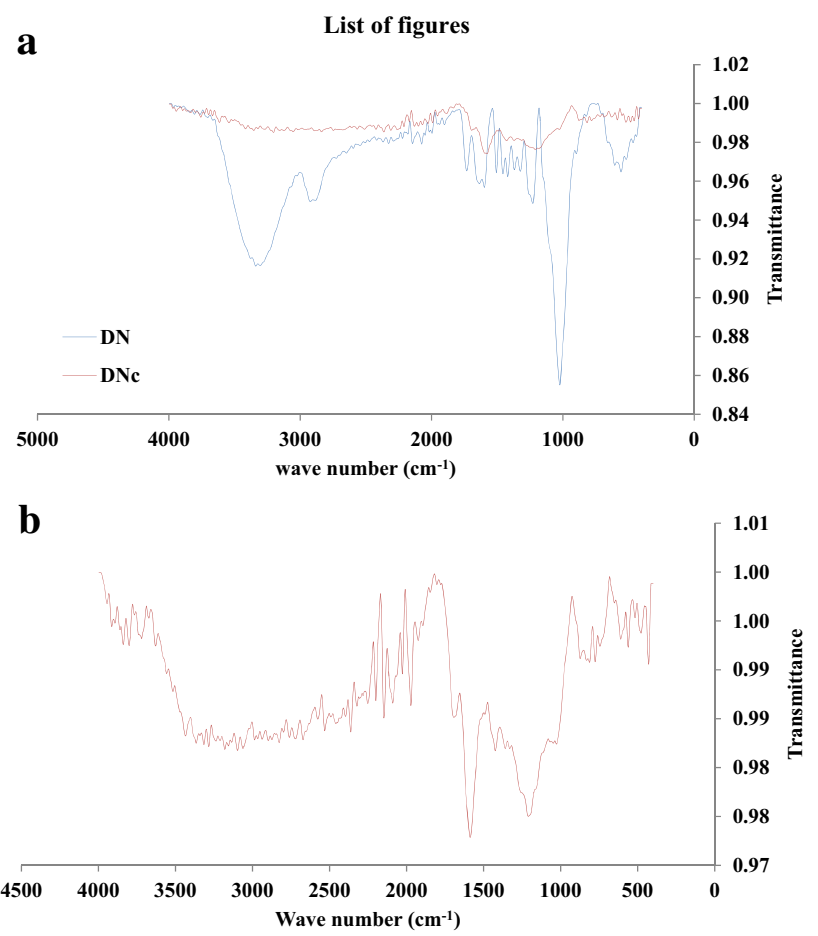

Fig. 1 a FTIR spectral of DN and DNc. b FTIR spectrum of CCDNc

surface morphology of DNc (Fig. 2a) with that of DN which was reported in a previous work (Inyinbor et al. 2015), thermal treatment results in the creation of pores of various shapes and sizes. Release of water in the matrix coupled with volatilization of volatile organic compounds due to thermal treatment may have resulted in the formation of these pores. A smooth surface coating of chitosan is, however, evident on CCDNc (Fig. 2c) while CCDNc maintains the basic structure of DNc. The smooth surfaces of the adsorbents before RhB adsorption were, however, rough after RhB uptake (Fig. 2b, d).

\section{Effect of pH on Rhodamine B uptake onto DNc and CCDNc}

Sharp increase in percentage adsorption was observed between $\mathrm{pH}$ of 2 and 4 within the RhB-CCDNc system, maximum percentage removal was recorded at $\mathrm{pH} 4$ (76.72\%) after which percentage adsorption dropped drastically. About $47 \%$ percentage removal was recorded for $\mathrm{pH} 9$ (Fig. 3). However, for the RhB-DNc system, optimum adsorption was obtained at $\mathrm{pH}$ of 3 while adsorption percentage decreased after $\mathrm{pH}$ of 3 . At low $\mathrm{pH}$, the surface of the adsorbent is highly positively charged. Repulsion between the cationic RhB molecules and positively charged adsorbent surface, results in low adsorption. As the $\mathrm{pH}$ of $\mathrm{RhB}$ solutions increased, the number of hydroxyl ions increased; thus 

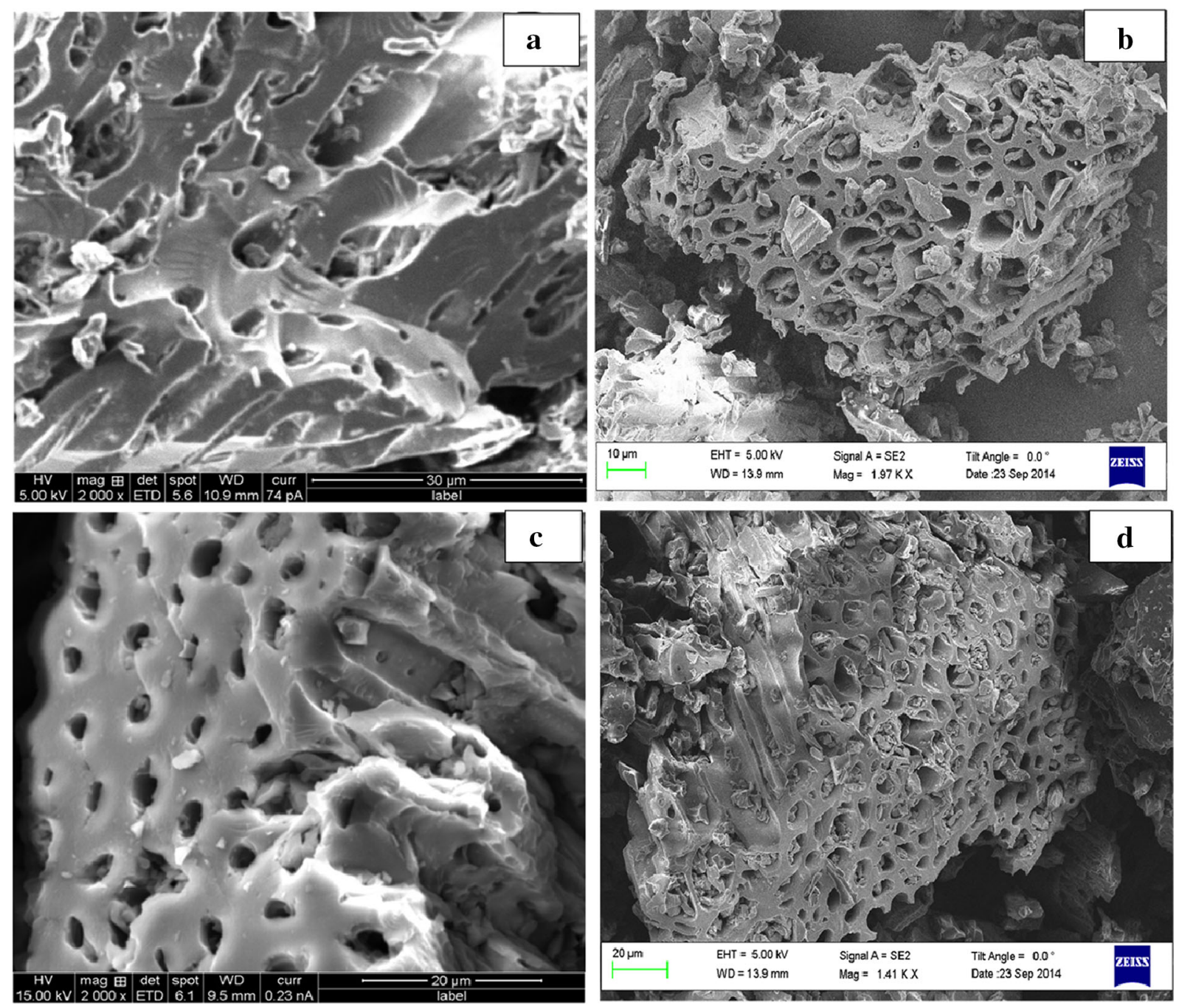

Fig. 2 SEM of DNc before RhB adsorption (a) and after RhB adsorption (b); SEM of CCDNc before RhB adsorption (c) and after RhB adsorption (d)

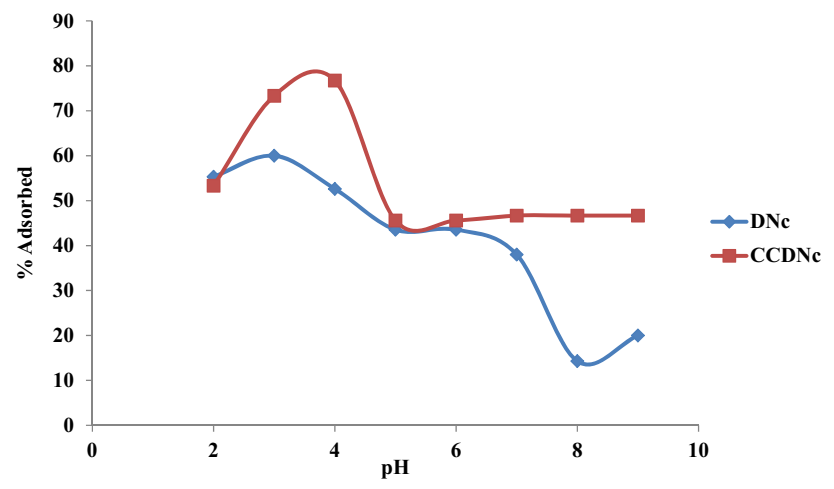

Fig. 3 Effects of $\mathrm{pH}$ on the percentage removal of Rhodamine B onto DNc and CCDNc. [Conditions: adsorbent dose $(1 \mathrm{~g} / \mathrm{L})$, agitation speed $(130 \mathrm{rpm})$, agitation time $(60 \mathrm{~min})$, Temperature $\left(26^{\circ} \mathrm{C}\right)$, Adsorbate concentration $(100 \mathrm{mg} / \mathrm{L})],(n=3,0 \leq \% E \geq 0.02)$ attraction between the cationic $\mathrm{RhB}$ and adsorbent surface is facilitated and subsequent increase in $\mathrm{RhB}$ uptake results. However, at $\mathrm{pH}$ above $3.7, \mathrm{RhB}$ exists in its zwitterionic form, thus facilitating attraction between the carboxyl and xanthenes groups of $\mathrm{RhB}$ monomers into the formation of larger molecules of $\mathrm{RhB}$ (dimers). The sorption of these large RhB molecules (dimer) becomes difficult resulting in decrease in adsorbent adsorption capacity. Maximum sorption of $\mathrm{RhB}$ at $\mathrm{pH}$ between 3 and 4 have been previously reported by researchers using cedar cone, rice hull based silica and kaolinite as adsorbents (Zamouche and Hamdaoui 2012; Gan and Li 2013; Bhattacharyya et al. 2014). 
Scheme 1 Proposed reaction between RhB and Chitosan

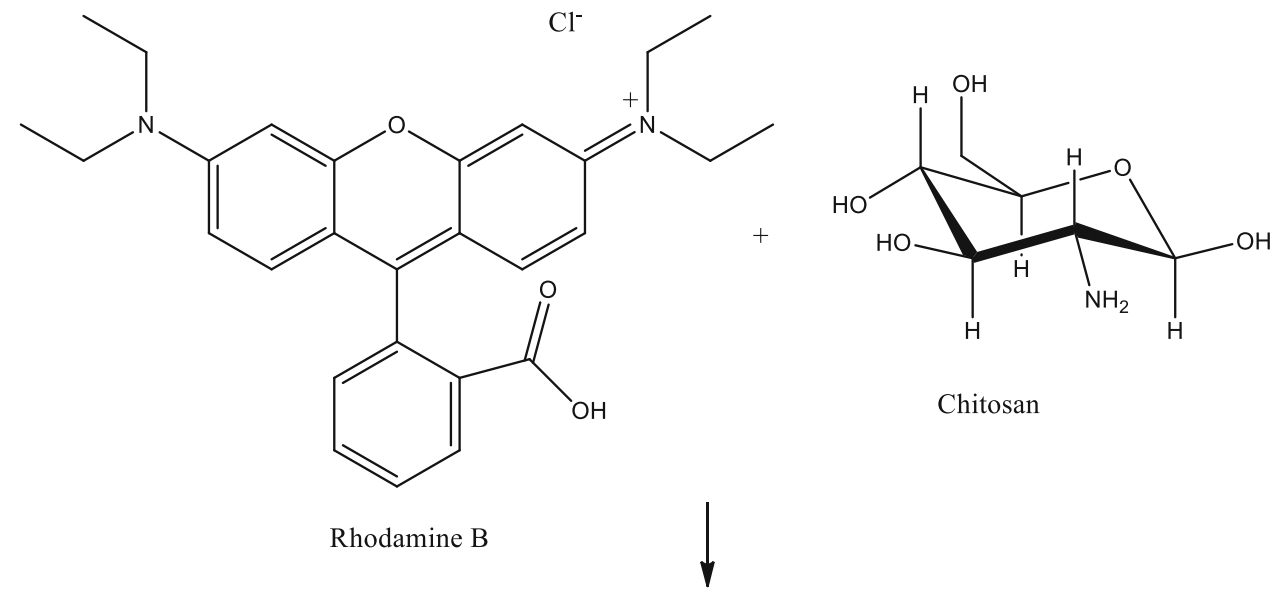

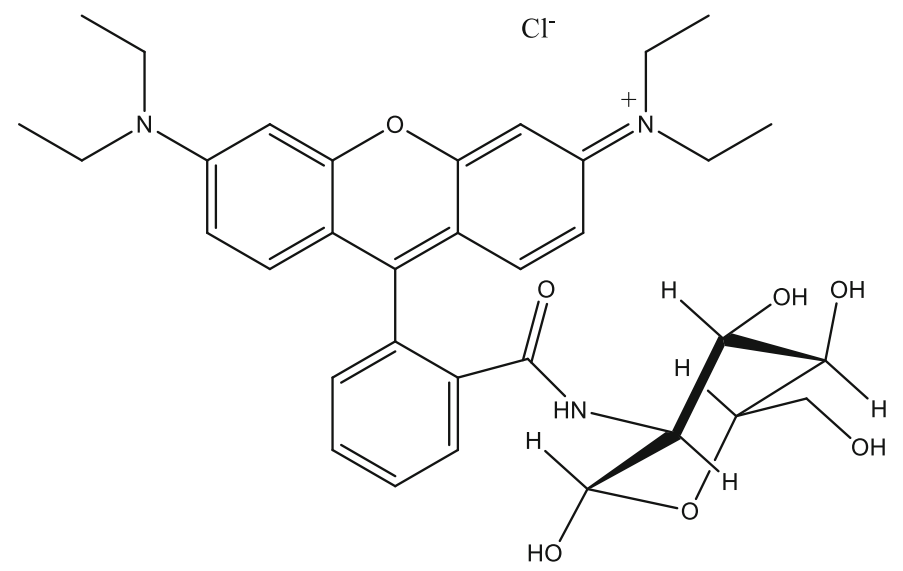

Isothermal studies of RhB adsorption onto DNc and $C C D N C$

Calculated parameters for the various isotherms are as presented in Table 3. The dimensionless $R_{L}$ value was obtained to be less than 1 suggesting favourable adsorption of RhB onto DNc and CCDNc. While the adsorption of RhB onto DNc was onto a homogenous surface $\left(R^{2}\right.$ value of Langmuir $=0.9632)$, multilayer adsorption occurred in RhB-CCDNc system $\left(R^{2}\right.$ value for Freundlich $\left.=0.9292\right)$. Uptake of RhB in the RhB-CCDNc system must have been first onto the reactive sites on the surface coating and subsequently percolation into the pores. Adsorbate-adsorbate interactions may also account for heterogeneity of the adsorption RhB-CCDNc system $\left(R^{2}\right.$ value of Temkin $=0.9084)$ (Bhattacharyya et al. 2014). Chitosan coating greatly enhanced the $q_{\max }, q_{\max }$ for DNc and CCDNc were 52.90 and $217.39 \mathrm{mg} / \mathrm{g}$, respectively. The adsorption energy $(E)$ obtained using the D-R model was 4.07 and $9.13 \mathrm{~kJ} / \mathrm{mol}$ for RhB-DNc and RhB-CCDNc systems, respectively. This suggests that while physisorption governs the uptake of RhB onto DNc, the uptake of RhB onto CCDNc followed a chemical process. Maximum monolayer sidered (Fig. 4a, b). 

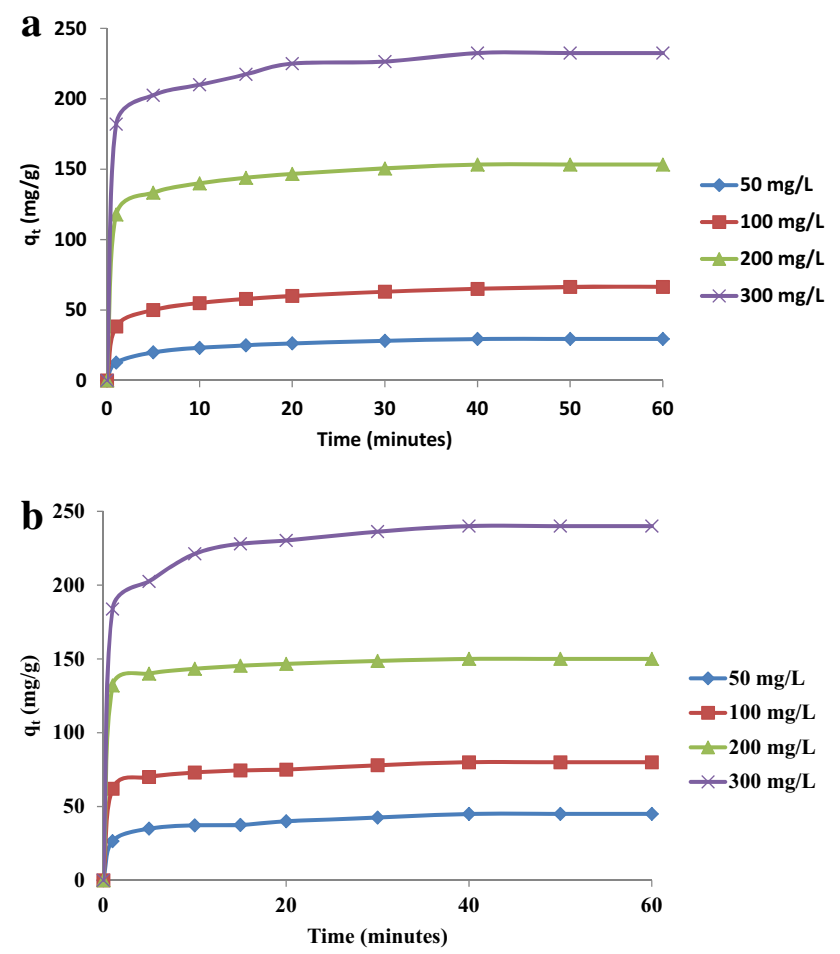

Fig. 4 a Effects of contact time and initial dye concentration on the uptake of RhB onto DNc [conditions: adsorbent dose $(1 \mathrm{~g} / \mathrm{L})$, agitation speed $(130 \mathrm{rpm})$, temperature $\left.\left(26^{\circ} \mathrm{C}\right), \mathrm{pH} 3\right],(n=3$, $0 \leq \% \quad E \geq 0.96$ ). b Effects of contact time and initial dye concentration on the uptake of $\mathrm{RhB}$ onto CCDNc. [conditions: adsorbent dose $(1 \mathrm{~g} / \mathrm{L})$, agitation speed $(130 \mathrm{rpm})$, temperature $\left.\left(26^{\circ} \mathrm{C}\right), \mathrm{pH} 4\right],(n=3,0 \leq \% E \geq 0.98)$

Table 3 Parameters of Langmuir, Freundlich, Temkin and D-R adsorption isotherm for the uptake of RhB onto DNc and CCDNc

\begin{tabular}{llcc}
\hline Isotherms & Constants & $\mathrm{DNc}$ & $\mathrm{CCDNc}$ \\
\hline Langmuir & $q_{\max }(\mathrm{mg} / \mathrm{g})$ & 52.90 & 217.39 \\
& $K_{L}\left(\mathrm{~L} \mathrm{mg}^{-1}\right)$ & 0.07 & 0.04 \\
& $R_{L}$ & 0.04 & 0.08 \\
& $R^{2}$ & 0.9632 & 0.8926 \\
Freundlich & $K_{F}$ & 12.72 & 15.1 \\
& $n$ & 3.29 & 1.61 \\
Temkin & $R^{2}$ & 0.7016 & 0.9292 \\
& $B$ & 10.89 & 43.96 \\
& $A(\mathrm{~L} / \mathrm{g})$ & 1.08 & 0.471 \\
& $b(\mathrm{~J} / \mathrm{mol})$ & 229.04 & 56.74 \\
D-R & $R^{2}$ & 0.6989 & 0.9084 \\
& $q_{o}\left(\mathrm{mg}^{2} \mathrm{~g}\right)$ & 45.84 & 149.44 \\
& $\beta\left(\mathrm{mol}^{2} \mathrm{~kJ}^{-2}\right)$ & 0.03 & 0.006 \\
& $E\left(\mathrm{kJmol}{ }^{-1}\right)$ & 4.07 & 9.13 \\
& $R^{2}$ & 0.8624 & 0.6731 \\
\hline
\end{tabular}

adsorption capacities of DNc and CCDNc were compared with other $q_{\max }$ previously reported in literature (Table 4) and CCDNc particularly exhibited better performance.
Kinetics studies of RhB adsorption onto DNc and CCDNc

Calculated parameters from the various kinetics plots is presented in Table 5, $R^{2}$ value for the pseudo second order kinetic ranged between 0.9980 and 0.9999 across concentrations considered while $R^{2}$ values for the Elovich model ranged between 0.9713 and 0.9978 (Table 5). Negligible differences exist between the $\mathrm{q}_{\mathrm{e}}$ experimental and the $q_{e}$ calculated, thus the values of $X^{2}$ for the two models were found to be generally less than 1 . This suggests that Pseudo second order kinetics and Elovich models suitably described the kinetics of $\mathrm{RhB}$ uptake onto DNc and CCDNc. Large values were recorded for $X^{2}$ in the case of Pseudo first order and Avrami kinetics models suggesting that the kinetics of RhB uptake onto DNc and CCDNc was not described by Pseudo first and Avrami kinetic models. The increase in chemisorption rate $(\alpha)$ as initial concentration increased further affirms that more than one mechanism ruled the uptake of $\mathrm{RhB}$ onto DNc and CCDNc (Ahmad et al. 2015). $R^{2}$ values for the intraparticle diffusion model ranged between 0.8400 and 0.9056 (Table 5) suggesting that the adsorption of $\mathrm{RhB}$ onto DNc and CCDNc may be controlled by intraparticle diffusion model. The value of $\mathrm{C}$ increased with initial $\mathrm{RhB}$ concentration, suggesting an increase in boundary layer effect as initial concentration increased. The graphs of $q_{t}$ against $t^{1 / 2}$, however, did not pass through the origin indicating some degree of boundary layer diffusion.

\section{Effects of temperature and thermodynamic studies}

Quantity of RhB adsorbed decreased with increased temperature for the two adsorbents. Quantity adsorbed decreased from 80.00 to $26.57 \mathrm{mg} / \mathrm{g}$ and from 66.50 to $19.58 \mathrm{mg} / \mathrm{g}$ for CCDNc and DNc, respectively, as temperature increased from 27 to $60{ }^{\circ} \mathrm{C}$ (Fig. 5). Increase in temperature may have resulted in reduction in binding force between the adsorbent and adsorbate thus resulting in decrease in adsorbent's adsorption capacity at high temperature. This is in agreement with previously reported work using polymeric gel as adsorbent (Malana et al. 2010). Table 6 lists the calculated thermodynamic parameters. Negative enthalpies $\left(\Delta H^{\circ}\right)$ obtained for the uptake of $\mathrm{RhB}$ onto the adsorbents indicates that the adsorption process was exothermic in nature. The negative values of $\Delta S^{\mathrm{o}}$ (Table 6) indicate decrease in the randomness at the solid-liquid interface during adsorption of $\mathrm{RhB}$ onto $\mathrm{DNc}$ and CCDNc. As the temperature increased from 300 and $333^{\circ} \mathrm{K}, \Delta G^{\mathrm{o}}$ values ranged between -1.71 and 3.91 for $\mathrm{RhB}$ uptake onto $\mathrm{DNc}$ and -3.46 and 2.81 for for $\mathrm{RhB}$ uptake onto CCDNc. Adsorption process was initiated, spontaneous and feasible at room temperature, however, at higher temperature adsorption process could not be 
Table 4 Comparison of the maximum monolayer adsorption capacity $\left(q_{\mathrm{max}}\right)$ of $\mathrm{RhB}$ onto $\mathrm{DNc}$ and $\mathrm{CCDNc}$ with others reported in literature

\begin{tabular}{lrl}
\hline Adsorbent & $\begin{array}{c}q_{\mathrm{max}} \\
(\mathrm{mg} / \mathrm{g})\end{array}$ & References \\
\hline Modified coir pith & 14.90 & $\begin{array}{l}\text { Sureshkumar and } \\
\text { Namasivayam 2008 }\end{array}$ \\
Bakers' yeast & 25.00 & Yu et al. 2009 \\
Cedar cone & 4.55 & Zamouche and \\
& & Hamdaoui 2012 \\
Sugarcane baggase & 51.50 & Zhang et al. 2013 \\
Calcined Mussels shells & 45.67 & El Haddad et al. 2014b \\
Microwave treated nilotica leaf & 24.39 & Santhi et al. 2014 \\
Acid treated kaolinite & 23.70 & Bhattacharyya et al. 2014 \\
Acid treated montmorillonite & 188.67 & Bhattacharyya et al. 2014 \\
Dika nut char & 52.90 & This study \\
Chitosan coated dika nut char & 217.39 & This study \\
\hline
\end{tabular}

sustained efficiently. This may be attributed to increased adsorbate-solvent interaction rather than adsorbate-adsorbent interaction at higher temperature (Malana et al. 2010).

Desorption studies of RhB-DNc and RhB-CCDNc systems

Desorption efficiencies follows the order $\mathrm{CH}_{3} \mathrm{COOH}>$ $\mathrm{HCl}>\mathrm{H}_{2} \mathrm{O}$ for the two adsorbents. In the case of CCDNc, desorption efficiencies were 59.09, 45.46 and $9.09 \%$ for $\mathrm{CH}_{3} \mathrm{COOH}, \mathrm{HCl}$ and $\mathrm{H}_{2} \mathrm{O}$, respectively. Highest desorption efficiency recorded by $\mathrm{CH}_{3} \mathrm{COOH}$ further affirms that uptake of RhB onto CCDNc was by chemisorption (Bello et al. 2008). In the case of DNc, desorption efficiencies were $81.82,68.18$ and $63.64 \%$ for $\mathrm{CH}_{3} \mathrm{COOH}, \mathrm{HCl}$ and $\mathrm{H}_{2} \mathrm{O}$, respectively. High desorption efficiencies recorded for DNc suggests that RhB was weakly bonded to DNc. Energy of adsorption obtained from the D-R model being

Table 5 Comparison of Pseudo first order, Pseudo second order, Elovich, Avrami and intra particle diffusion kinetic model parameters for the adsorption of RhB onto DNc and CCDNc

\begin{tabular}{|c|c|c|c|c|c|c|c|c|}
\hline \multirow[t]{3}{*}{ Constants } & \multicolumn{8}{|c|}{ Initial concentration } \\
\hline & \multicolumn{4}{|l|}{$\mathrm{DNc}$} & \multicolumn{4}{|l|}{$\mathrm{CCDNc}$} \\
\hline & 50 & 100 & 200 & 300 & 50 & 100 & 200 & 300 \\
\hline$q_{e}$ Experimental $(\mathrm{mg} / \mathrm{g})$ & 29.50 & 66.50 & 153.34 & 232.50 & 45.00 & 80.00 & 150.01 & 240.00 \\
\hline \multicolumn{9}{|l|}{ Pseudo first order } \\
\hline$q_{e}$ calculated $(\mathrm{mg} / \mathrm{g})$ & 26.8 & 25.75 & 33.64 & 46.66 & 16.55 & 16.11 & 17.03 & 55.46 \\
\hline$K_{1} \times 10^{-3}\left(\min ^{-1}\right)$ & 13.51 & 7.01 & 8.37 & 7.51 & 6.21 & 6.83 & 8.50 & 9.17 \\
\hline$R^{2}$ & 0.8764 & 0.9894 & 0.9898 & 0.9456 & 0.9518 & 0.9575 & 0.9891 & 0.9832 \\
\hline$X^{2}$ & 0.27202 & 64.49 & 425.92 & 740.17 & 48.91 & 253.38 & 1038.38 & 614.05 \\
\hline \multicolumn{9}{|l|}{ Pseudo second order } \\
\hline$q_{e}$ Calculated $(\mathrm{mg} / \mathrm{g})$ & 30.96 & 68.49 & 156.25 & 238.09 & 46.51 & 81.30 & 151.52 & 243.9 \\
\hline$K_{2} \times 10^{-3}\left(\mathrm{~g} \mathrm{mg}^{-1} \mathrm{~min}^{-1}\right)$ & 11.61 & 7.01 & 7.19 & 4.64 & 9.63 & 12.50 & 15.56 & 4.80 \\
\hline$R^{2}$ & 0.9988 & 0.9999 & 0.9998 & 0.9997 & 0.9980 & 0.9996 & 0.9999 & 0.9998 \\
\hline$X^{2}$ & 0.0689 & 0.0578 & 0.0542 & 0.1312 & 0.049 & 0.0208 & 0.01505 & 0.06236 \\
\hline \multicolumn{9}{|l|}{ Elovich } \\
\hline$\alpha_{E 1}(\mathrm{mg} / \mathrm{g} \cdot \min )$ & 90.91 & 1676.99 & $4,545,931.38$ & $1,143,295.33$ & 1432.39 & $4,259,397.66$ & $1.72 \times 10^{13}$ & $3,766,087.78$ \\
\hline$\beta_{E 1}(\mathrm{~g} / \mathrm{mg})$ & 0.2333 & 0.1415 & 0.1105 & 0.0766 & 0.2157 & 0.2208 & 0.2184 & 0.0676 \\
\hline$R^{2}$ & 0.9904 & 0.9978 & 0.9899 & 0.9855 & 0.9800 & 0.9898 & 0.9890 & 0.9713 \\
\hline$X^{2}$ & 0.042 & 0.0166 & 0.0389 & 0.0375 & 0.0069 & 0.0085 & 0.0108 & 0.0865 \\
\hline \multicolumn{9}{|l|}{ Avrami } \\
\hline$n_{\mathrm{Av}}$ & 0.5821 & 0.3815 & 0.2794 & 0.2584 & 0.3153 & 0.242 & 0.2189 & 0.3027 \\
\hline$K_{\mathrm{av}}\left(\min ^{-1}\right)$ & 1.3013 & 0.6197 & 1.1378 & 1.3909 & 0.4323 & 1.5029 & 3.1722 & 0.9207 \\
\hline$R^{2}$ & 0.8929 & 0.9633 & 0.9525 & 0.9351 & 0.9535 & 0.9511 & 0.9365 & 0.9373 \\
\hline$X^{2}$ & 476.53 & 3193.33 & $15,799.68$ & $37,604.2$ & 1656.85 & 4582.09 & $13,854.40$ & $37,416.26$ \\
\hline \multicolumn{9}{|l|}{ Intra particle diffusion } \\
\hline$C_{1} \times 10^{2}\left(\mathrm{mg} \mathrm{g}^{-1}\right)$ & 0.14 & 0.40 & 1.21 & 1.85 & 0.28 & 0.63 & 1.34 & 1.88 \\
\hline$K_{\text {diff }}\left(\mathrm{mg} \mathrm{g}^{-1} \min ^{-1 / 2}\right)$ & 2.31 & 3.86 & 4.87 & 7.11 & 2.57 & 2.47 & 2.46 & 7.93 \\
\hline$R^{2}$ & 0.8641 & 0.8953 & 0.8624 & 0.8816 & 0.9056 & 0.8890 & 0.8573 & 0.8400 \\
\hline
\end{tabular}




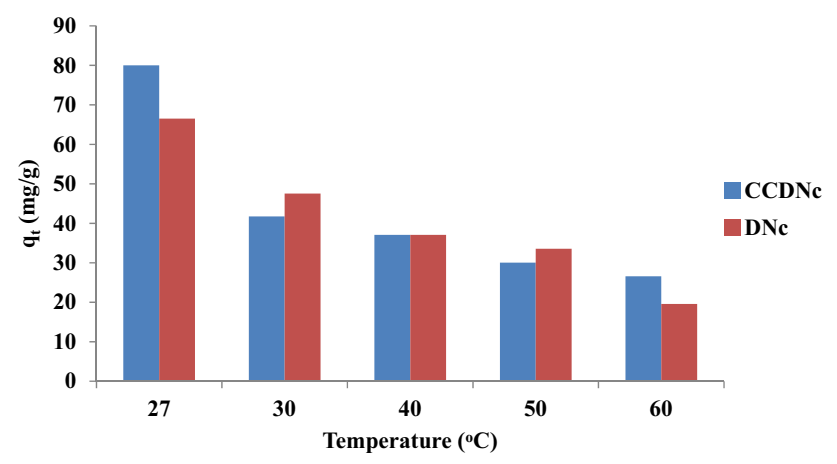

Fig. 5 Effects of temperature on RhB uptake onto DNc and CCDNc. [conditions: adsorbent dose $(1 \mathrm{~g} / \mathrm{L})$, agitation speed $(130 \mathrm{rpm})$, adsorbate concentration $(100 \mathrm{mg} / \mathrm{L}), \mathrm{pH} 3(\mathrm{DNc}) \mathrm{pH} 4$ (CCDNc)], $(n=3,0 \leq \% E \geq 0.32)$

Table 6 Thermodynamics parameters for adsorption of RhB onto CCDNc

\begin{tabular}{llllllll}
\hline Adsorbents & $\Delta H^{\mathrm{o}}$ & $\Delta S^{\mathrm{o}}(\mathrm{J} / \mathrm{mol} /$ & \multicolumn{6}{l}{$\Delta G^{\mathrm{o}}(\mathrm{KJ} / \mathrm{mol})$} \\
\cline { 5 - 8 } & $(\mathrm{KJ} / \mathrm{mol})$ & $\mathrm{K})$ & 300 & 303 & 313 & 323 & 333 \\
\hline $\mathrm{DNc}$ & -43.94 & -143.40 & -1.71 & 0.25 & 1.38 & 1.83 & 3.91 \\
$\mathrm{CCDNc}$ & -45.97 & -148.70 & -3.46 & 0.84 & 1.38 & 2.27 & 2.81 \\
\hline
\end{tabular}

less than $8 \mathrm{~kJ} / \mathrm{mol}$ also suggests that physisorption dominates the adsorption process of the RhB-DNc system.

\section{Conclusion}

Prepared adsorbents were effective for RhB uptake from aqueous solution. Isothermal models suggest that monolayer adsorption dominates the uptake of $\mathrm{RhB}$ onto $\mathrm{DNc}$ while uptake of RhB onto $\mathrm{CCDNc}$ was onto multi site. Surface modification greatly enhanced adsorption capacity with maximum monolayer adsorption capacities being 52.90 and $217.39 \mathrm{mg} / \mathrm{g}$ for DNc and CCDNc, respectively. Pseudo second order kinetic and Elovich models best described the kinetic of the adsorption system. Energy of adsorption obtained from the D-R model and desorption efficiencies suggests that adsorption of RhB onto CCDNc was by chemisorption while the uptake of $\mathrm{RhB}$ onto $\mathrm{DNc}$ was by physisorption. The uptake of RhB at high temperature was unfavorable while desorption of $\mathrm{RhB}$ from the adsorbents surface was easy and feasible.

Open Access This article is distributed under the terms of the Creative Commons Attribution 4.0 International License (http:// creativecommons.org/licenses/by/4.0/), which permits unrestricted use, distribution, and reproduction in any medium, provided you give appropriate credit to the original author(s) and the source, provide a link to the Creative Commons license, and indicate if changes were made.

\section{References}

Aharoni C, Ungarish M (1976) Kinetics of activated chemisorptions. Part I: the non-Elovichian part of the isotherm. J Chem Soc Farad Trans 72:265-268

Ahmad MA, Ahmad N, Bello OS (2015) Modified durian seed as adsorbent for the removal of methyl red dye from aqueous solutions. Appl Water Sci 5:407-423

Akar ST, Yilmazer D, Celik S, Balk YY, Akar T (2013) On the utilization of a lignocellulosic waste as an excellent dye remover: modification, characterization and mechanism analysis. Chem Eng J 229:257-266

Avrami M (1940) Kinetics of Phase Change: transformation-Time Relations for Random Distribution of Nuclei. J Chem Phys 8:212-224

Banerjee S, Sharma GC, Gautam RK, Chattopadhyaya MC, Upadhyay SN, Sharma YC (2016) Removal of Malachite Green, a hazardous dye from aqueous solutions using Avena sativa (oat) hull as a potential adsorbent. J Mol Liq 213:162-172

Bello OS, Adeogun IA, Ajaelu JC, Fehintola EO (2008) Adsorption of methylene blue onto activatedcarbon derived from periwinkle shells: kinetics and equilibrium studies. Chem Ecol 24(4):285-295

Bhattacharyya KG, SenGupta S, Sarma GK (2014) Interactions of the dye, Rhodamine B with kaolinite and montmorillonite in water. Appl Clay Sci 99:7-17

Deveci H, Kar Y (2013) Adsorption of hexavalent chromium from aqueous solutions by bio-chars obtained during biomass pyrolysis. J Ind Eng Chem 19:190-196

Dubinin MM, Radushkevich LV (1947) Equation of the characteristic curve of activated charcoal. Proc Acad Sci Phys Chem USSR 55:331-333

El Haddad M, Mamouni R, Saffaj N, Lazar S (2012) Removal of a cationic dye-basic red 12-from aqueous solution by adsorption onto animal bone meal. J Assoc Arab Univ Basic Appl Sci 12:48-54

El Haddad M, Slimani R, Mamouni R, El Antri S, Lazar S (2013) Removal of two textile dyes from aqueous solutions onto calcined bones. J Assoc Arab Univ Basic Appl Sci 14:51-59

El Haddad M, Regti A, Slimani R, Lazar S (2014b) Assessment of the biosorption kinetic and thermodynamic for the removal of safranin dye from aqueous solutions using calcined mussel shells. J Ind Eng Chem 20:717-724

Freundlich HMF (1906) Over the adsorption in solution. Z Phys Chem 57:385-470

Gan PP, Li SFY (2013) Efficient removal of Rhodamine B using a rice hull-based silica supported iron catalyst by Fenton-like process. Chem Eng J 229:351-363

Hameed BH, Mahmoud DK, Ahmad AL (2008) Equilibrium modeling and kinetic studies on the adsorption of basic dye by a lowcost adsorbent: coconut (Cocos nucifera) bunch waste. J Hazard Mater 158:65-72

Ho YS, McKay G (1999) Pseudo-second order model for sorption processes. Proc Biochem 34:451-465

Huang G, Wang D, Ma S, Chen J, Jiang L, Wang P (2015) A new, low-cost adsorbent: preparation, characterization, and adsorption behavior of $\mathrm{Pb}(\mathrm{II})$ and $\mathrm{Cu}(\mathrm{II})$. J Colloid Inter Sci 445:294-302

Inyinbor AA, Adekola FA, Olatunji GA (2015) Adsorption of rhodamine B dye from aqueous solution on Irvingia gabonensis biomass: kinetics and thermodynamics studies; S. Afr J Chem 68:115-125

Lagergren S, Svenska BK (1898) On the theory of so-called adsorption of materials. R Swed Acad Sci Doc 24:1-13

Langmuir I (1916) The constitutional and fundamental properties of solids and liquids. J Am Chem Soc 38:2221-2295 
Malana MA, Ijaz S, Ashiq MN (2010) Removal of various dyes from aqueous media onto polymeric gels by adsorption process: their kinetics and thermodynamics. Desalination 263:249-257

Meng Qin and Lu Dewei (2000) Biosorption of $\mathrm{Ni}^{2+}$ and $\mathrm{Fe}^{3+}$ by fungal cell wall saccharides. Chin J Chem Eng 8(2):123-127

Mohan D, Rajput S, Singh VK, Steele PH, Pittman CU Jr (2011) Modeling and evaluation of chromium remediation from water using low cost bio-char, a green adsorbent. J Hazard Mater 188:319-333

Salleh MAN, Mahmoud DK, Abdul Kareem WAW, Idris A (2011) Cationic and anionic dye adsorption by agricultural solid wastes: a comprehensive review. Desalination 280:1-13

Santhi T, Prasad AL, Manonmani S (2014) A comparative study of microwave and chemically treated Acacia nilotica leaf as an eco friendly adsorbent for the removal of rhodamine B dye from aqueous solution. Arab J Chem 7:494-508

Sayğ1l H, Güzel F (2016) High surface area mesoporous activated carbon from tomato processing solid waste by zinc chloride activation: process optimization, characterization and dyes adsorption. J Clean Prod 113:995-1004

Sheshmani S, Ashori A, Hasanzadeh S (2014) Removal of Acid orange 7 from aqueous solution using magneticgraphene/chitosan: a promising nano-adsorbent. Int J Biol Macromol 68:218-224

Slimani R, El Ouahabi I, Abidi F, El Haddad M, Regti A, Laamari MR, El Antri S, Lazar S (2014) Calcined eggshells as a new biosorbent to remove basic dye from aqueous solutions: thermodynamics, kinetics, isotherms and error analysis. J Taiwan Inst Chemical Eng 45:1578-1587

Sureshkumar MV, Namasivayam C (2008) Adsorption behavior of direct red 12B and Rhodamine B from water unto surfactantmodified coconut coir pith, Colloid and surfaces A: Physicochemical and Eng. aspects 317(1-3):277-283

Temkin MI, Pyzhev V (1940) Kinetics of ammonia synthesis on promoted iron catalyst. Acta Physiochimica USSR 12:327-356

Weber WJ, Morris JC (1963) Kinetics of adsorption on carbon from solution, J. Sanity Eng. Div Am Soc Civil Eng 89:31-59

Yu J, Li B, Sun X, Jun Y, Chi R (2009) Adsorption of methylene blue and rhodamine B on baker's yeast and photocatalytic regeneration of the biosorbent. Biochem Eng J 45:145-151

Zamouche M, Hamdaoui O (2012) Sorption of Rhodamine B by cedar cone: effect of $\mathrm{pH}$ and ionic strength. Energy Procedia 18:1228-1239

Zhang Z, O’Hara Ian M, Kent Geoff A, Doherty William OS (2013) Comparative study on adsorption of two cationic dyes by milled sugarcane bagasse. Ind Crops Prod 42:41-49

Zhao S, Zhou F, Li L, Cao M, Zuo D, Liu H (2012) Removal of anionic dyes from aqueous solutions by adsorption of chitosanbased semi-IPN hydrogel composites. Compos B 43:1570-1578 